\title{
Beyond str8tus quo: Urbanization and queerness in tropical Southeast Asia
}

\author{
Yvette Yanwen Lim \\ Nanyang Technological University, Singapore
}

\begin{abstract}
In response to the International Day of the Tropics, I have chosen to focus on the relationship between urbanization, space and bodies in tropical Southeast Asia. Through an analysis of films from the Philippines, Thailand and Singapore, I argue that urbanization continues to perpetuate heteronormativity and patriarchy even as economic indicators show human progress in measurable terms. The trajectory of progress towards diversity and inclusion in tropical Southeast remains fraught with challenges, especially when we examine how bodies interact with spaces and continue to observe oppression and restriction of non-normative expressions and performances. The questions that guide this paper are related to the relationships between urbanization, bodies and sexuality, and how these are articulated in spaces. Queer spaces include those of contests and contestation, of impermanence and transgression, and of malls and borders.
\end{abstract}

Keywords: urbanization, space, queerness, Southeast Asia, tropics

\section{Writing from the tropics: To know where l'm coming from}

With very few exceptions, the idea of the tropics as a place of pestilence has dominated European thought and action. Indeed, the temperate world's interpretation of the tropics has lurched from pestilence to paradise, but rarely has the zone been taken on in its own terms (State of the Tropics, 2014, p. 1).

Qtudies have pointed to the relationship between queer theory and location. In her research on

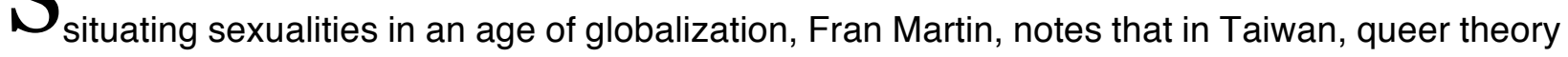
appeared in academic cultures in the late 1980s and early 1990s, as a result of the influence of migrant intellectuals returning to Taiwan from the US and Europe (2003, p. 2). These academics working in queer discourse brought with them new awakenings and theoretical insights surrounding queer cultures, diaspora literature, and artistic consciousness. This is pertinent, as it demonstrates that when moved to a new location, such as from the West to Taiwan, sexuality can be articulated and performed differently, or given new meanings and embodiment. It also 
suggests that drawing on concepts and issues surrounding geographies, locations and space is a meaningful way to add to queer discourse. Furthermore, boundaries that separate countries are often arbitrary and unstable, depending on historical and political factors, and this mirrors the way queerness both destabilizes categories, and can be approached as affected by temporality and space.

Andrew Grossman notes that "sexual minorities are universal, but their interpretations, and more so their politicizations, are not" (Grossman, 2000, xvi). Framing his work on queer Asian cinema, effectively situates the importance of interpretations of queer expressions, moving beyond discussions of queer identities. This paper attempts to contribute to research on the tropics, and the International Day of the Tropics, by opening up to the discourse on queerness through the analysis of films from three countries in Southeast Asia, namely the Philippines, Thailand and Singapore. For the purposes of this paper, the chosen film texts all have a strong sense and use of space - from bars and the difficult transition from rural to urban space, to the strategic use of shopping malls. These film texts point towards a fresh way of approaching queer bodies located in urban Southeast Asia; not simply in relation to sexual identities, but more in connection with how characters express themselves through the spaces they occupy, how they play out their lives and experiences. ${ }^{1}$ At the same time, this paper observes that urbanization continues to perpetuate patriarchy and heteronormativity, despite the 'progress' measured by economic indicators.

\section{Queer spaces as locality of contests}

Situated at the cross roads of East and West, and riding on the waves of globalization, how located bodies in films from tropical Southeast Asia play out their queerness in relation to being simultaneously local and global has transformed this region in many ways. This becomes a relevant premise on which to build this paper, since the film texts to be analyzed have urban (and sometimes rural) locations, and transverse between being local and global. Queer spaces should be understood not as distinct zones of difference, but perhaps as a 'locality of contests' between normative expectations and non-normative desires and contact. For films set in cities like Manila, Bangkok or Singapore, how the forces of globalization are played out, and how these shape postmodernities and the constructions of spaces and sexualities in these cities can be enriching to the discourse on queer geographies. Judith Halberstam (2005) has suggested more crosscultural studies need to be done on queer lives in non-metropolitan areas, as urban spaces and the city have often been projected as a liberated place more conducive to formations of queer identities, resulting in narratives that often equate the journey of moving from small town to big

\footnotetext{
${ }^{1}$ In light of its grammatical function as a verb, noun and adjective, this paper sees "queer" not simply as an identity category, but more as a strategy that can be employed to situate bodies "within postmodernist and/or post-structuralist frameworks which decenter normative notions of sexuality" (Johnston \& Longhurst, 2010, p. 13), which points to myriad possibilities of how gender and sexuality norms can be challenged and debated in the framework of a postmodern consciousness in the twenty-first century. As a strategy of the performativity of sexuality, queerness can be embodied in multiple ways $(1993,2004,2007)$.
} 
eTropic 15.2 (2016): 'International Day of the Tropics' Special Edition I 96

city as a journey parallel with moving from the closet to being out and proud. While this paper does not simply employ the uses of metropolitan versus non-metropolitan spaces, it does take as significant the configuration of spaces and locations as critical to the emergence and performance of queerness.

The film The Blossoming of Maximo Oliveros (Solito, 2005) tells the story of twelve-year-old Maxi who lives in the slums of Manila with his father and brothers, who make a living as petty thieves. Maxi is deeply loyal to his family of petty thieves, with his world revolving around his father and two brothers. They love and protect him, and Maxi demonstrates his devotion to his family by dutifully completing domestic chores and sticking up, or covering up, for them when they commit crimes. The dramatic tension stems from the conflict between Maxi's family's illegal livelihood and his affection for the young, handsome police officer Victor. Maxi and Victor quickly become friends after they meet, but the friendship soon leads to various disputes with Maxi's family, which gets further complicated when his brother commits murder in a robbery gone wrong. Maxi is stuck between protecting his family and being honest to his friend (TLA Releasing, n.d.). In the film, queer moments emerge through the reimagining of the dark slums of the streets of Manila as queer space. Maxi's pre-teen body and the roles he plays in drag in the spaces that he occupies serve to draw out the parallel between a crossing of genders and the crossing of unstable spaces; a confusion which performativity mirrors the body being "out of place".

Keith Ulrich, in his review of The Blossoming of Maximo Oliveros notes that the film it is groundbreaking in taking as its subject matter "the developing sexual feelings of children, a subject most easily infantilized, sensationalized, or brushed under the carpet" in Western cultures (Ulrich, 2006). Other reviews note that "the camera often follows him as he gyrates his hips and sashays through his neighborhood streets, with confidence and attitude, as if he were commanding a fashion runway" (Klemm, 2009) - a reference to how Maxi's body navigates his surroundings and projects a transformative power over the slums of Manila. Even as some critics note that the film charms "with its refreshingly blasé handling of homosexuality, its amiable actors and its delicacy of milieu", I posit that the movie presents an argument regarding how the ambiguous body works as a way to express not just queerness, but also a way to challenge normativity through the concept of being out of place, queering the locations they occupy through fleeting moments of stability.

Sara Ahmed offers up a model of how "bodies are gendered, sexualized, and raced by how they extend into space", a framework that lays out "how bodies become orientated by how they take up time and space" (Ahmed, 2006, p. 5). She suggests that "if orientation is about making the strange familiar through the extension of bodies into space, then disorientation occurs when that extension fails" (Ahmed, 2006, p. 11), which also points to the possibility that some spaces extend certain bodies and simply do not leave room for others, leaving some bodies "out of place" and "rootless". Her elaborate discussion on orientations and queer phenomenology takes into account 
how bodies navigate through spaces and how "disorientation" happens when things or bodies are "out of place" (Ahmed, 2006, p. 10). Orientation is a term of particular note here, as it can refer to sexuality, direction, as well as location. The relationship between orientation and location is an interesting one. To go on a path that is not conventional (read, normative) is to choose a queer way out, and that orientation speaks both of sexuality, as well as where one goes to place oneself in the larger scheme of things governed by heteronormativity. Building on her theorizing on queer phenomenology, I argue that the film Maximo Oliveros (Solito, 2005) is more than a movie about the coming of age of an effeminate boy. Maxi's body functions as an aporetic device which challenges normative expectations about gender, bodies, kinship and what Judith Halberstam (2005) calls the 'reproductive and familial time' and the 'logic of capital accumulation', as both temporality and location face disruptions from heteronormative developments.

Performance of cross-dressing and overt displays of conventional femininity signal the pre-teen body's constant drifting in and out of locations: between light and darkness, justice and criminality, legitimacy and the underground. His body is queered in many ways because of constant drifting in the following ways: the ostensible gender roles switching or cross-dressing; a subversion of conventional domestic roles; and the teetering between legal and illegal lives. In other words, the confusing visual spectacle manifested in his bodily confusion is mirrored in the constantly shifting locations that he occupies - his home, the police station, the dark alleys and the streets. Just as he tries to balance or find a way to navigate between light and darkness, so is his body trying to find a way to navigate between its gendered performances.

There are times when the body - including Maxi's body - acts in certain ways that violate boundary and space, and upset the harmony of the body being in place, thus rendering it "out of place". Bell and Valentine (1995) note that the body can be read as a space and how it performs in space allows room for interpretation, as it "marks a boundary between the self and other, both in a literal physiological sense but also in a social sense. It is a personal space" (Bell \& Valentine, 1995 , p. 15). In other words, when the concept of the body becomes an opposition of Self and Other, the stage is set for various collisions of binaries such as the personal and the public, which leads to the blurring of boundaries and the challenging of expected norms. For a body to be "in place", it usually has to subscribe to, or abide by, rules inscribed in heteronormativity. The idea of the flexible body might also be extended into how bodies considered abject, "out of place" or those that do not fit within prescribed sexual norms are expected to be disciplined.

\section{Of impermanence and transgression}

Queerness can be approached as more than just identifying as someone who is nonheterosexual; it can be approached more as a political statement, a strategy, and performance of sexuality that proposes to challenge social norms governed by heteronormative ideals. Rather than speaking about how queer might be identity, I want to argue for the idea that queerness 
might emerge as a result of a combination of the time and space that bodies occupy. I look at how queer emerges through its association with the night, impermanence, the illicit and transgressive; and examine these variations of queerness in relation to bodies that acquire queer meanings because of the darker and marginal spaces they inhibit. As our bodies navigate through physical (and with the internet also virtual and imaginary) spaces every day, the ways bodies relate to locations, and what locations do to bodies, illustrate how sexualities are negotiated and performed in specific pockets of time and space.

Mary Douglas's arguments about how dirt is conceptually defined as matter out of place proves useful here. Dirt is approached in our culture as 'bad/corrupt' because it disrupts perceived order. The metaphorically "dirty" sexual body is the body which "transgresses the borders of respectability and respectable places. It is the body that is constituted within brothels, alleyways, public parks, back streets, public bathrooms, 'wrong' beds, dark and illicit spaces" (Douglas, cited in Johnston \& Longhurst, 2010, p. 27). Such transgression of spaces culturally marked as respectable, or disrespectable, points to how locations and spaces can queer bodies: in the dark and hidden corners are queer lives living out their existence.

For settings such as gay bars and macho dancing bars in films like Lino Brocka's Macho Dancer (1988), it is more than just about identifying the bodies that occupy these spaces as gay or bisexual, and more about being located in a space that is often associated with the underground, the secretive, and the ephemeral that makes these spaces and dancers queer. The same can be said about bodies that navigate mean streets (Macho Dancer), and those teetering on borders of legitimate and illegal lives (Saint Jack, The Blossoming of Maximos Oliveros). In Lino Brocka's Macho Dancer (1988), the setting moves from a rural village, where the male protagonist Paul originates, to a big urban city with bars and pubs. He is forced to move to the city to make a living after splitting with his American lover, and once introduced to the city, he makes his livelihood as a macho dancer at a gay bar. His transition from a simple world in the countryside to a complex urban world of darkness and sin brings with it anxiety and expectations. His sexuality is mapped across landscapes of both rural and urban, and its performance marked by time and location. The setting of the gay bar queers bodies occupying that location not by assuming that everyone who is in there as a performer or spectator identifies as gay (although that might well be the case), but through several layers of spatial meaning. For one thing, this location and the act of "macho dancing" are "about the night" - queerness is located in this specific pocket of time and space in the nightlife scene, without which queerness cannot be performed. The early scenes in the countryside have an openness to them - the generous use of wide spaces convey a sense of freedom, even if the dilapidated houses reveal much about Paul's socioeconomic status. Forced by circumstances, he has to leave his mother and siblings to earn a living in the city. Looking forward to a life of comfort ahead, little does he expect to inhabit some of the most dingy spaces of Manila. He is first brought to a macho dancing night club, where he is confronted with a row of naked men dancing seductively with foam on their bodies to entertain the audience. His worth is 
measured by his eagerness to learn, and how attractive his body is, effectively objectifying Paul to the audience's gaze. The highly anticipated move to the big city from the countryside only places Paul in an ever more vulnerable position to the gaze - even as he gains economic independence and prosperity.

Other than the macho dancer night club, which is a specific locality where queerness is produced by means of the men's dancing bodies and their interaction with other bodies and the space they occupy during the few hours they are at work, the other locations featured in the movie likewise add to the sense of queer by being either shrouded in darkness, or operating at night (such as supper spots and at late night cinema). Moreover, the pub where Paul works is also named in a gender-confused manner. 'Mama Charlie's Pub', is a colorful nightspot that caters to people seeking entertainment in the form of "macho dancers". In an extended scene where two macho dancers perform a bathing scene, the men lovingly caress each other on stage, heightening the homoerotic desires that are played out with slow and sensual music, adding to the drawn-out cinematic caress of the men's torsos. The shot cuts to Paul, who looks on with a bewildered expression, then cuts back to the couple again, lingering on their entwined bodies covered in soap for a few more seconds, before it cuts to a scene in the bedroom that Paul shares with his roommate. The abrupt transition from a scene loaded with homoerotic desires to one where two friends share a quick chat before retiring to bed seems to suggest that queer is indeed about the night, that performances of marginal and alternative sexuality take place and thrive in a contained environment like the macho dancer club, whose meaning and worth reside in the dark (Brocka, 1988).

On another level, within specific pockets of time and locations, power relations are contested and even reversed as the male bodies on display become hypersexualized, often in a feminized manner, aided by costume (or the lack thereof), body movements, and music that is often comprised of "heterosexual romantic ballads by female singers and go-go dancers singing slow rock" (Tolentino, 2009, pp. 83-84). While it might seem that the more economically prosperous patrons and spectators of the bathing performances in the film are more powerful because of their affluence and their gaze upon the macho dancers' bodies, the hierarchy of power could be queered as "the real phallic power remains to be negotiated based on the terms of the macho dancer" (Tolentino, 2009, p. 84), since their success depends on how much the patron desires the bodies on display. This specific location queers the film because the moment of being in the gay bar itself transforms performances of sexuality and renders them non-normative. Whether the patron is a man or a woman, their desires and gazes, when projected onto the sensual dancing bodies, cannot simply be categorized based on identity politics. They are continually contested, questioned, hovering on the margins.

With the characters navigating through space marked as dangerous and marginalized (escaping from forced prostitution, for instance), the settings and their implications recall Douglas's 
arguments about how dirt and abjection are always related to notions of disorder, and how these queer and abject bodies tend to be framed or situated in places considered less respectable (Douglas, 1966, pp. 47-59). These bodies are almost always framed by the illicit and the secretive. In a group dancing scene, we see all the macho dancers at Mama Charlie's Pub doing their best to keep to the rhythm while gyrating their hips, wearing nothing more than skimpy underwear and accessories, which highlight the theatrics of their performance. The shots are often drawn out to showcase the interior of the night club, which serves to emphasize the fact that everyone who is in the space of the club at that point in time is complicit in the partaking and the production of that queer moment and performance. This complicity is confirmed by another extended shot of the bathing performance between two of the macho dancers later in the film. As the camera lens caresses the two performers while they stroke each other, the shots often turn to acknowledgement from the audience as men and women nod their approval of the raunchy dance. The location bears significance to the emergence of queerness in this instance, not only because it provides a platform for the homoerotic desires performed, but also because of the collectivity and complicity of both performance and audience, for the macho dancing bar would not be in existence if not for the demand for queerness to be housed in this location with a specific purpose.

In its marginalization, queer is almost always situated on the sidelines and deprived of any respectability in the conventional sense. The film's arguments about living on the edge in a Philippines steeped in corruption and political incompetence during the time of Marcos and Aquino also queer it by locating it in a politically-charged and marginal space that is unstable and impermanent, and rendering it different from mainstream Filipino cinema. The framing of the streets and slums of Manila also allows for a remapping and re-imagination of the lives that inhabit these spaces, crafting out a domain for these marginalized lives apart from (yet a part of) a more prosperous capital city.

\section{Transgressions, censored}

Over the last thirty to fifty years, Singapore has evolved from an entrepôt port city to a modern, globalized city-state. While the country has modernized itself economically, restrictions on freedom of expression remain in place in the form of censorship of objectionable films and other media. Today, the mean streets, whore houses, and triad rivalries which were rampant in the 1970s have been erased or contained, the urban city-state now identified internationally by mega structures that cement Singapore's status as a cosmopolitan city. In 1979, under the guise of a dummy movie title, Saint Jack (Corman, Morfogen, Novak \& Bogdanovich, 1979) became the first Hollywood film shot entirely in Singapore. The movie was later banned on the grounds that there would be excessive edits involved due to scenes of nudity and coarse language. Saint Jack is a film by Peter Bogdanovich, based on the novel by writer Paul Theroux (1973), about an American 
pimp called Jack Flowers living in Singapore. The film is set mainly in the late 60 s and early 70 s and takes us through various incidents and adventures in Flower's life, including working as a ship's chandler on Boat Quay, running a brothel, being attacked by gangsters and working for the US government on various shady operations (Slater on NLB blog, 2006).

The ban on the film was only lifted in Singapore after almost thirty years, and the movie was given a screening at the National Museum of Singapore in 2009 as part of a program entitled Once Upon a Time in the Orient that documents foreign takes on Singapore/Malaya. On the subject of lifting the ban, Ben Slater, who wrote a book about the production of the movie, has this to say:

One thing I say in the book is that Singapore has changed radically, so that was never in doubt! Censorship is still a daily reality in Singapore, but I feel that the unbanning of Saint Jack is a very crucial symbolic act - the film stands in for a past that Singapore's authorities have spent 28 years trying to eradicate, so by saying "You can watch it now", it is finally accepting that it's OK for people to reconsider those times. But the fact remains, the world of Saint Jack has disappeared. You can't go back there, but you can now take a look at the movie. (Slater on NLB Blog, 2006)

The censorship of the film not only removes from the consciousness of most Singaporeans the sights and sounds of what Singapore used to be, but also shuts out the specific locations that contained elements of street life (such as pimping, brothels, gang fights) that have never sat well with the authorities in Singapore. In preventing the broadcast of the film, the authorities have relegated the mean streets and illicit lives of a Singapore of the past into the margins. This past Singapore is sidelined forever through censorship, demolished effortlessly from the minds of many Singaporeans, who are forced to quietly accept the rapid urbanization and gentrification of the island state. It is ironic that it is through this active censorship that, contrary to what they were trying to do, the authorities have in fact queered the film by censoring it and placing the film in the sidelines of people's collective consciousness. Even as the authorities in Singapore continue to clamp down on vices that are frowned upon, it remains evident that these activities - the illicit and the forbidden - can still find time and space to exist, by locating themselves in the dark and in the transient moments of the night.

Even as that world of darkness, the illicit and illegal, is sidelined and carefully managed by the authorities, I argue that the location of the film - in the rebellious world of Singapore in the 1970s - simultaneously queers the bodies through impermanence (the fact that it no longer exists today, due to censorship of the film and also urbanization of the city). By pushing them onto the edges of society, the film and its censorship, deny the bodies and the locations the right to exist both physically and in the consciousness of the public. Furthermore, the censorship is in itself an attempt to reinstate heteronormativity, as the film also contains queer moments of homoerotic tensions and suspense where young boys are sent to older men for pleasure, set against the backdrop of the Vietnam War as Jack is offered the opportunity by the CIA to run a brothel for the $R \& R$ activities of U.S. soldiers on leave in Singapore (International Movie Data Base, 2012). The 
scene featuring homoerotic tension, however, is never shown in its entirety. It is shrouded in partial darkness, obscured by the intricate framing of the camera, which makes it seem like the audience were spying on the scene, creating a sense of complicity and suspense - which further marks that space as illicit and strange, only existing in the temporal framework of the night and the space of the hotel room.

The film Saint Jack has all the transgressions that the Singapore authorities want to shut out, eliminate, or push into the background - from prostitution, gangs and shady dealings, to homoerotic desires - and its queerness emerges from these moments of transgressions and association with the impermanent and the illicit. The space of the whore house, for instance, is a domain that “doesn't come about easy, takes a lot to move, takes a lot of hustling' (Saint Jack, Corman et al., 1979), and is a space that is only meaningful insofar as it can operate without being busted and remain intact in the illicit spaces and temporality of the night. The location of Bugis Street is a case in point for how locatedness matters in the emergence of queerness and the queering of bodies. In the film, what takes place on Bugis Street in the day (when people sell food) and at night (when transvestites and prostitutes walk the street) are marked by the transition of time, which give the bodies that navigate the street at different pockets of time different meaning. Here, Douglas's thoughts about the metaphorically "dirty" sexual body that is constituted within brothels, alleyways, dark and illicit spaces proves relevant again, as the transvestite bodies and prostitutes are not queer because of their sex and gender performativity, but they can be read as queer because they are marginalized and set apart from heteronormative conventions as a result of the time and spaces that they navigate. As a motif, Bugis Street functions in the film as the breeding ground of all that is unmentionable in a country that treasures orderliness and disapproves of chaos. Bugis Street at night is a world where anything goes - where foreigners such as Jack Flowers are brave enough to place their ambitions in dominating the brothel scene in Singapore, taking on violent local Chinese triads in a bloody battle for territories, where queer lives can acquire meaning of their own by making a living on the margins of the society - and this lack of governance in 1970s in Singapore is precisely what gives the film its energy and bold imagination.

\section{Navigating malls and borders: A path that isn't right}

Siam Square, a commercialized area in the heart of Bangkok that is popular with Thai teenagers, features as one of the key settings for the movie Love of Siam, a popular Thai movie packaged as a teen romance with a queer twist (Pinkaew, Vongsthapat, \& Sakveerakul, 2009). In its cinematic exploration of the theme of teen romance, the mall is a location that serves as a platform where the main characters, Tong and Mew, struggle with their queerness. In one poignant scene, Tong's mother, Sunee, confronts Mew about their developing relationship. Sunee declares, "You know how our family has suffered. Tong is all we have left, and I don't want to see him taking a path that isn't right." She then goes on to explain to Mew, "In the future, after Tong has graduated, 
he should hunt for a job, save money, and look for a good wife, get married and have a warm family where they can take care of each other in old age. That is life, Mew...and I raised Tong so that he would grow up that way" (Love of Siam, 2009). The mother never directly mentions Tong and Mew's queer relationship, but by describing it as a "path that isn't right", her character personifies the overarching system of heteronormative beliefs, and hints at queerness as occupying a divergent path and orientation. Her metaphoric explanation seems to suggest that a queer life - one that is lived outside of heteronormative expectations spatially or chronologically in Judith Halberstam's thinking (Halberstam, 2005) - can be configured as one grounded in where you go and where you are, rather than merely who you are; thus bringing to attention the relationships between locatedness and queerness. This example of Tong's mother's interpretation of her son's queerness is grounded in the rhetoric of his queer behavior as an act of going down a "path that isn't right", thereby situating the body in a manner distinct from heteronormative expectations. The phrasing and crafting of such distinctions as straight or notstraight also point to a more basic phenomenological awareness that where and how bodies are located often point to the ways in which they can be queered. Conversely, Tong's mother seems to believe that as long as she steers Tong back on to the "right path", and offers him a "straight" life, then his queer behavior would disappear. This again seems to suggest that where bodies are located and the paths they choose can shed light on interpretations of queer, and how bodies interact with their locations also play a part in whether or not they are interpreted as queer.

Likewise, Singaporean film maker Eric Khoo's Be With Me (Hong \& Khoo, 2005) offers up an interesting site for spatial and queer analysis for several reasons, "not only because of these geographies of identity, but also because Khoo engages with (and gently critiques) some of the social and spatial consequences of Singapore's development agenda" (Law, Wee \& McMullan, 2011 , p. 363). ${ }^{2}$ Space is a limited commodity in Singapore, but more often than not, the way people reclaim and reimagine the spaces they navigate gives it more meaning and makes these spaces larger than life. The film is of note also because it is the first Singapore film to explicitly feature a lesbian relationship in the segment of the film entitled "So In Love". The way the homoerotic tension is suggested develops slowly such that "the audience does not suspect more than friendship is at stake until a scene in the cinema where the camera pans from their feet, across their intertwined hands and to their faces" (Law, Wee, \& McMullan, 2011, p. 368). This extended suspense of the queer feelings developing between the two girls achieves the effect of

\footnotetext{
2 In countries that were former British colonies like Malaysia and Singapore, the penal code 377(A), which criminalizes homosexual acts between men is still in existence, together with laws governing media and artistic content. Thus, while queer films are not always banned, the line that writers and film makers in Singapore, for instance, tread is a thin one, which balances between being critical and staying within legal boundaries. While there is still tension between local attitudes across Southeast Asia towards alternative sexual practices and a more widespread acceptance of queer film in public or in subcultural groups, globalization and transnational cultural discourses (queer or otherwise) increasingly intertwine issues of geographies and locations with desires and sexualities, which sets the scene for this paper's inquiry into urbanization, space and queerness.
} 
gentle surprise for the audience because the shot has been set up as one that reproduces heteronormative coupling, as Jackie is in jeans and Sam is in a skirt. While this research wants to move away from labeling same-sex relationships as queer, their location (and the signs that mark it), how they occupy this location (lying side by side on a public pavement in the middle of the night), as well as how the shot is framed, collectively render the text and that cinematic moment queer.

The section of the film, "So In Love", is a teenage love story wherein the characters communicate the urgency of thoughts in instant messages on their hand phones (mobile phones), thus locating them in a networked space that is not governed by permanence - given that the 'delete' button is capable of obliterating their exchanges in a flash. There is a scene where the two teenage girls, Jackie and Sam, end their day of walking through malls and engaging in activities that typically connote some sort of romantic connection, by lying down on steps in the open space outside of the "Borders" book store. In a universe governed by normative social expectations, people lying down on steps in public might be viewed as a nuisance and be frowned upon. However, the darkness of the night and lack of passers-by situate them in a space and temporality that is away from the normative gaze, even though it remains a public space, so the ephemeral nature of their action is enhanced by the time and space they occupy. The camera takes a wide shot until the two bodies take up only a small portion of screen at the bottom left corner. More pointedly perhaps, the shot focuses on the word 'BORDERS', which really jumps out as a direct and rather literal metaphor of them lying beyond borders - or at the edge of borders, or about to cross borders - hinting at a sense of impending transgression and the challenging of heteronormative relationship patterns. The transgression of a girl-girl relationship, still finding its place in a society governed by heteronormativity, never comes to fruition, leaving one party rejected and longing for the other's attention. As Sam ceases to communicate with Jackie, giving up their relationship for one with a male classmate, Jackie sinks into a state of dejection, her efforts to reach out and connect with Sam never reciprocated. In a moment of desperation, Jackie's suicide attempt marks a poignant dénouement for this tale of queer feelings, as Jackie's anguish and her death are part of the argument that attempts to "normalize" queer love that it is no less intense or inferior than heteronormative feelings. The fact that their attempt to transgress heteronormative borders never succeeds adds a bittersweet touch to expression of queer feelings.

\section{Conclusion}

Even though there are cultural sensitivities and particularities involved that differ from country to country and from location to location in tropical Southeast Asia, some themes remain universal. Globalization is a force that pushes both ways: at the same time as it introduces the concept of unique individualism to collectivist cultures in this part of the tropical world, it also dilutes differences through the inundation of pop culture and Westernization. In this regard, globalization can be seen as a sweeping trend that makes the shopping mall a staple location in any 
modernized city. As a location that encapsulates the many faces of modern life - from shopping for groceries, watching a movie, to having dinner - the dynamic and manifold complications it introduces to human relationships will surely impact on an evolving interpretation of human interactions. Significantly, the shopping mall and the design of its shop spaces, have been developed with a heterosexual couple in mind. Even as cities in the Southeast Asian region rapidly urbanize, the construction of malls and the creation of such spaces continue to perpetuate heteronormativity and patriarchy, as laid out in the Thai film Love of Siam (Pinkaew et al., 2009). The way that non-heterosexual couples navigate this "straight" space and re-imagine that space as something they can embody presents interesting insights into the importance of spaces in the study of queer texts. As landscapes in tropical Southeast change with urbanization and gentrification, it becomes pertinent to explore if these 'developments' continue to reinforce a politics of patriarchy and heteronormativity through the design of infrastructure, or whether they allow for an opening towards a notion of progress inclusive of diversity - including non-normative expressions of sexualities.

\section{References}

Ahmed, S. (2006). Queer phenomenology: Orientations, objects, others. Durham, United Kingdom: Duke University Press.

Bell, D., \& Valentine, G. (Eds.). (1995). Mapping desire: Geographies of sexualities. London, United Kingdom: Routledge.

Brocka, L. (Director). (1988). Macho dancer [Motion picture]. Philippines: Viva Films.

Corman, R., Morfogen, G., \& Novak, B. (Producers) \& Bogdanovich, P. (Director). (1979). Saint Jack [Motion picture]. United States of America: New World Pictures.

Douglas, M. (1966). Purity and danger: An analysis of concepts of pollution and taboo. London, United Kingdom: Routledge \& Kegan Paul.

Grossman, A. (2000). Queer Asian cinema: Shadows in the shade. New York, NY: Harrington Park Press.

Halberstam, J. (2005). In a queer time and place: Transgender bodies, subcultural lives. New York, NY: New York University Press.

Hong, B. (Producer) \& Khoo, E. (Director). (2005). Be with me [Motion picture]. Singapore: Zhao Wei Films.

International Movie Data Base (2012). Saint Jack (1979). Retrieved from: http://www.imdb.com/title/tt0079843/?ref_=nv_sr_1.

Johnston, L. \& Longhurst, R. (2010). Space, place, and sex: Geographies of sexualities. Plymouth, United Kingdom: Rowman \& Littlefield Publishers.

Klemm, M.D. (2009, March). Secret Worlds [Blog post]. Retrieved from Cinema Queer.com: http://www.cinemaqueer.com/review\%20pages\%202/blossominglaleon.html

Law, L., Wee, C.J.W.-L., \& McMullan, F. (2011). Screening Singapore: The cinematic landscape of Eric Khoo's Be With Me. Geographical Research, 49, 363-374.

Martin, F. (2003). Situating sexualities: Queer representation in Taiwanese fiction, film andpublic culture. Hong Kong, China: Hong Kong University Press.

Pinkaew, P., \& Vongsthapat, S. (Producers) \& Sakveerakul, C. (Director). (2009). Love of Siam [Motion picture]. Thailand: Sahamongkol Film International.

Solito, A. (Director). (2005). The blossoming of Maximo Oliveros [Motion picture]. Philippines: UFO Picture Cinemalaya. State of the Tropics (2014). State of the Tropics Project Overview. Retrieved from: http://stateofthetropics.org/wp- 
content/uploads/Project-Overview_Final1.pdf.

Theroux, P. (1973). Saint Jack. New York, NY: Houghton Mifflin Harcourt Publishing Company.

TLA Releasing (n.d.). The blossoming of Maximo Oliveros [Web page]. Retrieved from: http://tlareleasing.com/films/theblossoming-of-maximo-oliveros/

Tolentino, R.B. (2009). Macho dancing, the feminization of labor, and neoliberalism in the Philippines. The Drama Review, 53, 77-89.

Ulrich, K. (2012). The blossoming of Maximo Oliveros. Slant Magazine, 8 March 2006. 